\title{
PENERAPAN KONSELING DENGAN PENDEKATAN KOGNITIF- BEHAVIORAL MENINGKATKAN PENYESUAIAN DIRI MAHASISWA AKADEMI KEBIDANAN AL-SUAIBAH PALEMBANG
}

\author{
Zulaikha Agustinawati \\ Dosen Akbid Al-Su'aibah \\ Jalan Sukabangun II Rt 24/04 No 1451 KM 6,5 Palembang \\ Sur-el: Zulaikhaagustinawati@yahoo.co.id
}

\begin{abstract}
Abstrak : This study aims to determine the description of the subject's self-adjusting behavior, find out the factors that cause self-adjustment in the subject, apply counseling with a behavioralcognitive approach to improve adjustment to the subject. This type of research uses qualitative methods with case studies. Data collection techniques use primary data where to obtain data using observation, interviews and analysis of written documents. The results of this study are: 1) experiencing fear when interacting with peers on campus, being unable to deal with problems, assessing themselves negatively, avoiding the environment, not having close relations with campus friends and being less able to control emotions; 2) inconsistent parenting namely authoritarian and permissive parenting, peer rejection is a dominant factor in $W^{\prime}$ s self-adjustment difficulties; 3) the effectiveness of counseling is seen from the difficulty of self-adjustment $W$ who has been able to challenge the irrational beliefs that are owned, can interact with peers on campus, realize that the importance of entering campus and follow the lecture material schedule and work on KTI (scientific writing), and more active talk to peer groups on campus.
\end{abstract}

Keyword: Counseling, Self-Adjustment, Cognitive-Behavioral

\begin{abstract}
Abstrak : Penelitian ini bertujuan untuk mengetahui gambaran perilaku penyesuaian diri subyek, menerapkan konseling dengan pendekatan kognitiv-behavioral untuk meningkatkan penyesuaian diri pada subyek. Jenis penelitian ini menggunakan metode kualitatif dengan studi kasus. Karakteristik subyek penelitian adalah mahasiswa tingkat III Akademi Kebidanan, perempuan, berusia 21 tahun, berkemampuan kognitif di atas rata-rata, mengalami kesulitan penyesuaian diri di sekolah serta bersedia menjadi subyek penelitian. Teknik pengumpulan data menggunakan data primer dimana untuk memperoleh data menggunakan observasi, wawancara dan analisis dokumen tertulis. Kesimpulan penelitian ini adalah: 1) mengalami ketakutan bila berinteraksi dengan teman sebaya di kampus, kurang mampu mengatasi masalah, menilai diri secara negatif, menghindari lingkungan, tidak mempunyai hubungan yang akrab dengan teman kampus serta kurang mampu mengendalikan emosi; 2) pola asuh inkosisten yaitu pola asuh otoriter dan permisif, penolakkan teman sebaya merupakan faktor kesulitan penyesuaian diri W yang dominan; 3) keefektifan konseling dilihat dari adanya kesulitan penyesuaian diri $\mathrm{W}$ yang telah mampu menantang keyakinan irasional yang dimiliki, dapat berinteraksi dengan teman sebaya di kampus, menyadari bahwa pentingnya masuk kampus dan mengikuti jadwal materi kuliah serta mengerjakan KTI (karya tulis ilmiah), serta lebih aktif berbicara dengan kelompok teman sebaya di kampus.
\end{abstract}

Kata Kunci: Konseling, Penyesuaian Diri, Kognitif-Behavioral

\section{PENDAHULUAN}

Penerapan Konseling dengan Pendekatan Kognitif-Behaviora......(IZulaikha Agustinawati) 
Setiap orang memerlukan kepercayaan diri untuk berhasil dalam hidupnya. Kepercayaan diri berperan dalam memberikan semangat serta motivasi individu untuk beraksi secara tepat terhadap tantangan dan kesempatan yang datang padanya maupun untuk merasakan berbagai keberhasilan dalam hidupnya. Kepercayaan diri mampu memberikan sumbangan bermakna dalam proses kehidupan seseorang, dan selanjutnya membantu pengembangan pribadi yang normal.

Menurut Kartono,k (2003) menyebutkan penyesuaian diri adalah usaha manusia untuk mencapai harmoni pada diri sendiri pada lingkungan, sehingga rasa permusuhan, dengki, iri hati, prasangka, depresi, kemarahan dan lainlain emosi negative sebagai respon pribadi yang tidak sesuai dan kurang efesien bisa dikikid habis. Kesesuaian diri dengan lingkungan diutarakan oleh Gerungan (2002) bahwa penyesuaian diri adalah mengubah diri sesuai dengan keadaan lingkungan dan mengubah lingkungan dengan keadaan dan keinginan sendiri.

Dari beberapa definisi tentang penyesuaian diri, maka dapat diambil kesimpulan bahwa penyesuaian diri adalah kemampuan penguasaan dalam mengembangkan diri dalam mengendalikan dorongan, emosi, dan kebiasaan menjadi terarah serta usaha individu untuk mengubah diri sesuai dengan tuntutan atau harapan lingkungan sosial demi mencapai suatu hubungan yang harmonis diantara diri dengan lingkungan.
Menurut Haber dan Ruyon

menyatakan bahwa karakteristik penyesuaian diri ada dua yaitu: 1) individu yang mampu menyesuaikan diri dan 2) individu yang kurang mampu menyesuaikan diri.

Gladding menyatakan bahwa bimbingan merupakan proses bantuan yang bertujuan membantu individu membuat keputusan penting dalam hidupnya. Sedangkan menurut pendapat Mcleod (2010) konseling merupakan bentuk pertolongan yang fokus pada kebutuhan dan tujuan seseorang.

Tujuan konseling yang dinyatakan oleh Corey (2009) berdasarkan klien yaitu bahwa tujuan konseling tergolong dalam sekelompok tujuan yang beraneka ragam, diantaranya adalah penyususnan kembali kepribadian, penemuan makna dalam hidup, penyembuhan gangguan emosional, penyesuain terhadap masyarakat, pencapaian kebahagian dan kepuasan, pencapaian aktualisasi diri, perbedaan kecemasan serta pengubahan tingkat laku maladaptif dengan mempelajari pola-pola tingkah laku adaptif.

Konseling pendekatan kognitif-behavioral yang digunakan dalam penelitian ini sebagaian besar bertujuan untuk memanajemen dan kontrol tingkah laku. Berbagai tujuan konseling di atas pada akhirnya ditujukan untuk membatu klien memecahkan masalah yang sedang dialami. Keberhasilan konselor mencapai tujuan konseling tergantung kepada pemahaman terhadap keadaan klien, yaitu kemampuan mengenal diri, mengambil keputusan, bertindak serta menjaga kekonsitenan diri untuk tetap Jurnal Ilmiah PSYCHE Vol.13 No.1 Juli 2019: 13 - 23 
melaksanakan hasil konseling meskipun konseling telah berakhir.

Progran konseling kognitif-behavioral dilaksanakan secara berurutan dimulai dari penciptaan hubungan yang sangat dekat konselor dengan klien, penerapan teknik intervensi samapi pada tahap mengakhiri program. Target perubahan perilaku dilakuakan oleh klien karena klien yang mengatahui sejauh mana kemampuan diri untuk melakukan perubahan serta perubahan yang seperti apa yang ingin dicapai. Oleh karena itu target perubahan disusun secara detil, jelas dan diperkirakan dapat dicapai sesuai dengan keadaan dan kemampuan klien yang bersangkutan.

Sama halnya seperti konseling yang lain, maka konseling kognitif-behavioral juga disertai dengan beberapa intervensi untuk membantu klien mencpai tujuan konseling. Haag dan Davidson serta Meinchenbaum (McLeod,2010) menyatakan bahwa teknik intervensi dalam konseling pendekatan kognitif-behavioral yang biasa digunakan seperti dibawah ini :

a. Menantang keyakinan irasional

b. Membingkai kembali isu; misalnya, menerima kondisi emosional internal sebagai sesuatu yang menarik ketimbang sesuatu yang menakutkan.

c. Mengulang kembali penggunaan beragam pernyataan diri dalam role play dengan konselor

d. Mencoba penggunaan berbagai pernyataan diri yang berbeda dalam situasi riil e. Mengukur perasaan; misalnya dengan menetapkan perasaan cemas yang ada saat ini skala $0-100$

f. Menghentikan pikiran cemas atau obsesional yang dominan

g. Desentisasi sistematis, yaitu mengganti respon takut atau cemas dengan respon releksasi yang telah dipelajari.

h. Pelatihan ketrampilan atau asertifikasi

i. Penugasan pekerjaan rumah dengan mempraktekan perilaku baru dan strategi kognitif.

j. In vivo exprosure, yaitu memasuki situasi paling menakutkan didampingi oleh konselor sebagai motivator.

Masing-masing intervensi dipilih berdasarkan keadaan dan masalah yang dialami oleh klien. Penerapan intervensi yang tepat dan cermat diharapkan mampu menciptakan perubahan perilaku klien. Intervensi yang digunakan didalam penelitian ini adalah : 1) menantang keyakinan ; 2) latihan relaksasi ( relaxation training) ; 3) mengukur parasaan dengan hiraki kecemasan dalam skala $0-100$; 4) latihan ketrampilan social (social skills training).

Tujuan penelitian ini adalah untuk mengetahui gambaran perilaku ketidak percayaan pada diri subyek, mengetahui faktor yang menyebabkan ketidak percayaan diri pada subyek dan menerapkan konseling dengan pendekatan kognitif-bahavioral untuk meningkatkan ketidak percayaan diri pada subyek. 
Di Akademi Kebidanan Al-Su'aibah Palembang, Direktur sekolahan tersebut merekomendasikan seorang mahasiswa yang pada saat ini, duduk di tingkat III dan berumur 21 tahun. Rekomendasi ini diberikan karena mahasiswa tersebut kurang memiliki rasa kepercayaan diri pada dirinya yang mengakibatkan mahasiswa tersebut menilai bahwa dirinya kurang memiliki kemampuan kognitif, merasa penampilan dirinya lebih buruk dari teman sebayanya, sering kabur dari asrama pada saat ada masalah dengan teman dikampus, sulit mengendalaikan emosi, sering menyendiri dari kelompok yang dianggapnya lebih dari dirinya, mudah putus asa, cenderung bergantung pada orang lain dalam mengatasi masalah khususnya dengan ibu, pernah mengalami trauma, sering berbohong agar dapat di terima oleh lingkungan yang menyebabkan rasa percaya dirinya semakin buruk dan memiliki prestasi akademik yang tergolong sedang.

Sesuai dengan keadaan diatas, maka pendekatan konseling yang paling sesuai dengan kondisi subyek adalah konseling dengan pendekatan kognitif-behavioral. McLeod (2010) menyatakan bahwa konseling pendekatan kongnitif-behavioral bertugas membantu klien untuk menentukan dan mengenali diri dan membuat pilihan tentang perilaku yang dipertahankan dan diubah. Konseling dengan pendekatan kognitif-bahavioral dipilih untuk mengopimalkan kemampuan kognitif subyek yang tegolong rata-rata (average) serta memberikan penghargaan yang selama ini belum sepenuhnya diterima dari lingkungan keluarga 16 maupun sekolah atas kemampuanya dalam menentukan masalah sendiri.

Teknik intervensi pada konseling dengan pendekatan kognitif-behavioral yang akan diterapkan adalah menantang keyakinan irasional, latihan releksasi, serta mengukur perasaan dengan membuat hiraki kecemasan (John Mcleod, 2010)

Berdasarkan uraian di atas peneliti tertarik melakukan penelitian tentang penerapan konseling dengan pendekatan kognitif-behavioral untuk meningkatkan penyesuaian diri pada mahasiswa di Akademi Kebidanan Al-Suaibah Palembang.

\section{METODOLOGI PENELITIAN}

Metode penelitian digunakan adalah metode penelitian kualitatif dengan studi kasus yang dilakukan untuk mengungkap kondisi kontekstual atau kenyataan hidup sehari-hari yang berhubungan dengan fenomena dari studi yang ingin diteliti melalui penggalian informasi secara empiris (Yin,2011). Penggunaan metode diharapkan dapat mengungkap gambaran serta sebab-sebab munculnya ketidak percayaan diri yang dialami oleh subyek penelitian secara mendalam.

Penelitian kualitatif dengan pendekatan studi kasus ini bertujuan untuk mengungkap informasi tentang subyek sehingga ditentukan faktor-faktor yang mempengaruhi informasi ketidak percayaan diri secara insentif dan mendalam. Informasi yang diungkapkan adalah :

Jurnal Ilmiah PSYCHE Vol.13 No.1 Juli 2019 : 13 - 23 
Latar belakang subjek, pola asuh orangtua, serta penyebab ketidak percayaan diri lainnya. Kemudian informasi yang telah ditemukan akan digunakan sebagai pendoman dalam menetapkan jenis intervensi yang efektif untuk mengatasi ketidak percayaan diri tersebut.

4. perempuan, berusia 21 tahun dan berprestasi sedang.

5. Mengalami ketidak percayaan diri sejak duduk dibangku akedemi kebidanan

6. Sering berbohong, tidak menempati janji

7. Bersedia menjadi subyek penelitian Jumlah subjek dalam penelitian ini satu orang agar dapat memperoleh informasi yang mendalam (Banister, dkk dalam Poerwandari, 1998)

Teknik pengumpulan data yang dilakukan dalam penelitian ini meliputi: 1. Observasi langsung non partisipan. 2. Wawancara terbagi menjadi dua, yaitu autoanamnesa dan alloanamnesa. 3.Tes Psikologi digunakan untuk mengumpulkan data psikologis tertulis tentang taraf kecerdasan, gambaran kepribadian, konsep diri, penyesuaian keluarga dan sosial serta kreatifitas bahasa subyek
Subyek penelitian ini memiliki beberapa karakteristik, yaitu:

3. Seorang mahasiswa tingkat III di Kebidanan Al-Su'aibah Palembang, berjenis kelamin

\section{HASIL DAN PEMBAHASAN}

\section{Hasil}

Peneliti menerapkan konseling dengan pendekatan kognitif-behavioral untuk meningkatkan penyesuaian diri W. Penyesuaian diri memiliki ciri-ciri yang sangat luas. Oleh karena itu intervensi ini di fokuskan untuk mengatasai penyesuaian diri pada $\mathrm{W}$ dalam hal: 1) kecemasan atau ketakutan jika berinterkasi dengan teman-teman, 2) gambaran diri yang negative, 3) kurangnya keaktifan untuk membina hubungan interpersonal dengan teman sebaya. Teknik intervensi yang digunakan adalah menantang keyakinan irasional, latihan relaksasi, serta latihan keterampilan. 
Identifikasi masalah

\begin{tabular}{|c|c|c|c|c|}
\hline No & $\begin{array}{l}\text { Perilaku sebelum } \\
\text { intervensi }\end{array}$ & Indikator Perilaku & Frekuensi & Intesitas \\
\hline 1. & $\begin{array}{l}\text { Merasa takut jika } \\
\text { berinteraksi dengan } \\
\text { teman }\end{array}$ & $\begin{array}{l}\text { Tangan keringatan, } \\
\text { menghindari interaksi } \\
\text { dengan teman sebaya } \\
\text { dalam kelompok, yakin } \\
\text { kalau menegur terlebih } \\
\text { dahulu maka akan tidak } \\
\text { balas, malu, menunduk }\end{array}$ & $5 \times$ Sehari & 80 \\
\hline 2. & $\begin{array}{lr}\text { Tidak } & \text { masuk } \\
\text { kampus } & \text { atau } \\
\text { (karena } & \text { tidak } \\
\text { nyaman } & \text { berada di } \\
\text { kampus) } & \end{array}$ & Daftar kehadiran (absensi) & $2 \mathrm{x}$ seminggu & 90 \\
\hline 3. & $\begin{array}{l}\text { Menghindari atau } \\
\text { tidak masuk kelas } \\
\text { pada materi tertentu } \\
\text { (merasa kurang } \\
\text { mampu menguasai } \\
\text { pelajaran karena } \\
\text { guru kurang jelas } \\
\text { menerangkan) }\end{array}$ & \begin{tabular}{lr} 
Daftar & \multicolumn{2}{r}{ kehadiran } \\
(absensi), nilai mata \\
pelajaran tersebut.
\end{tabular} & $1 \mathrm{x}$ seminggu & 80 \\
\hline 4. & $\begin{array}{l}\text { Tidak mengerjakan } \\
\text { tugas KTI (merasa } \\
\text { guru pembimbing } \\
\text { kurang jelas dalam } \\
\text { menerangkan) }\end{array}$ & $\begin{array}{l}\text { Buku paraf dosen } \\
\text { pembimbing }\end{array}$ & $3 \times$ seminggu & 80 \\
\hline 5. & $\begin{array}{l}\text { Bersikap pasif dan } \\
\text { merasa masa bodoh } \\
\text { ketika berada di } \\
\text { kelas dan asrama }\end{array}$ & $\begin{array}{l}\text { Jantung } \text { berdegup } \\
\text { kencang, menghindari } \\
\text { kelompok teman sebaya, } \\
\text { mudah tersinggung }\end{array}$ & $3 \times$ sehari & 80 \\
\hline
\end{tabular}

Dari tabel di atas dapat dijelaskan bahwa W diminta untuk menyebutkan frekuensi munculnya perilaku dalam 1 hari atau 1 minggu. Kemudian w menentukan intesitas masalah berdasarkan kategori yang telah peneliti susun sebelumnya. W diminta menilai masing-masing perilaku sebelum intervensi in dengan angka 1-100 (kelipatan 10) untuk mengetahui intesitas masing-masing. Apabila nilai yang diberikan oleh $\mathrm{w}$ semakin mendekati 100 , berarti masalah tersebut semakin berat begitu sebaliknya. 
Target Perilaku

\begin{tabular}{|c|c|c|c|}
\hline No & $\begin{array}{l}\text { Perilaku sebelum } \\
\text { intervensi }\end{array}$ & Indikator Perilaku & Target Perilaku \\
\hline 1. & $\begin{array}{l}\text { Merasa takut jika } \\
\text { berinteraksi dengan } \\
\text { teman }\end{array}$ & $\begin{array}{l}\text { Tangan keringatan, } \\
\text { menghindari interaksi dengan } \\
\text { teman sebaya dalam } \\
\text { kelompok, yakin kalau } \\
\text { menegur terlebih dahulu } \\
\text { maka akan tidak balas, malu, } \\
\text { menunduk }\end{array}$ & $\begin{array}{l}\text { Lebih berani menyapa } \\
\text { teman terlebih dahulu } \\
\text { (skor 40) }\end{array}$ \\
\hline 2. & $\begin{array}{l}\text { Tidak masuk kampus } \\
\text { atau bolos (karena } \\
\text { tidak nyaman berada } \\
\text { di kampus) }\end{array}$ & $\begin{array}{l}\text { Gelisa (merapikan jilbab } \\
\text { yang sudah rapi), ngomel, } \\
\text { merasa tidak betah, merasa } \\
\text { kesal. }\end{array}$ & $\begin{array}{lr}\text { Akan rajin } & \text { masuk } \\
\text { kampus } & \text { dangan } \\
\text { menciptakan suasana } \\
\text { yang nyaman di } \\
\text { kampus (skor } 30 \text { ) }\end{array}$ \\
\hline 3. & $\begin{array}{l}\text { Menghindari } r \text { atau } \\
\text { tidak masuk kelas } \\
\text { pada materi tertentu } \\
\text { (merasa kurang } \\
\text { mampu menguasai } \\
\text { pelajaran karena guru } \\
\text { kurang jelas } \\
\text { menerangkan) }\end{array}$ & $\begin{array}{l}\text { Gelisah (gerakan tangan } \\
\text { mengepal), menghindari } \\
\text { kegiatan belajar, sulit } \\
\text { konsentrasi, merasa kesal }\end{array}$ & $\begin{array}{lr}\text { Akan } & \text { mengikuti } \\
\text { jadwal } & \text { materi } \\
\text { pelajaran } & \text { dengan } \\
\text { menggunakan } & \text { sumber } \\
\text { tambahan } & \text { buku } \\
\text { 30) } & \end{array}$ \\
\hline 4. & $\begin{array}{l}\text { Tidak mengerjakan } \\
\text { tugas KTI (merasa } \\
\text { guru pembimbing } \\
\text { kurang jelas dalam } \\
\text { menerangkan) }\end{array}$ & $\begin{array}{lr}\text { Gelisa (tangan } & \text { keringatan, } \\
\text { mata merah, jantung } \\
\text { berdegup } & \text { kencang) } \\
\text { menghindari } & \text { kegiatan } \\
\text { bimbingan, merasa kesal }\end{array}$ & $\begin{array}{lr}\text { Akan mengerjakan } \\
\text { tugas KTI dengan } \\
\text { menggunakan sumber } \\
\text { tambahan buku, } \\
\text { internet. (skor 20) }\end{array}$ \\
\hline 5. & $\begin{array}{l}\text { Bersikap pasif dan } \\
\text { merasa masa bodoh } \\
\text { ketika berada di kelas } \\
\text { dan asrama }\end{array}$ & $\begin{array}{lr}\text { Jantung berdegup } & \text { kencang, } \\
\text { menghindari } & \text { kelompok } \\
\text { teman sebaya, mudah } & \\
\text { tersinggung } & \end{array}$ & $\begin{array}{l}\text { Lebih aktif berbincang } \\
\text { dengan kelompok } \\
\text { teman sebaya di } \\
\text { kampus (skor 40) }\end{array}$ \\
\hline
\end{tabular}

Berdasarkan tabel diatas, dapat dijelaskan bahwa berdasrkan intervensi yang telah dilakukan maka w telah berhasil menentukan target perubahan perilaku yang ingin dicapai. Hal ini terlihat dari perubahan perilaku $\mathrm{w}$ yang awalnya takut berinteraksi menjadi terlihat berani menyapa teman terlebih dahulu dan sudah dapat berinteraksi dengan target perubahan perilaku tersebut. 
Perubahan Keyakinan Irasional menjadi Lebih Rasional

\begin{tabular}{|c|c|c|c|}
\hline No & Keyakinan Irasional & Intervensi & Keyakinan Irasional \\
\hline 1. & $\begin{array}{l}\text { "Saya merasa teman- } \\
\text { teman membenci dan } \\
\text { mengacukan saya" }\end{array}$ & $\begin{array}{l}\text { "Apa buktinya bahwa } \\
\text { teman-teman } \\
\text { membenci dan } \\
\text { mengacukan saya" }\end{array}$ & $\begin{array}{lr} & \text { "Saya yakin bahwa } \\
\text { teman-teman } & \text { tidak } \\
\text { membenci } & \text { dan } \\
\text { mengacukan saya" } & \end{array}$ \\
\hline 2. & $\begin{array}{l}\text { "Saya merasa tidak } \\
\text { dihargai } \quad \text { sebagai } \\
\text { teman" }\end{array}$ & $\begin{array}{l}\text { "Apa buktinya bahwa } \\
\text { teman tidak } \\
\text { menghargai saya" }\end{array}$ & $\begin{array}{l}\text { "Saya yakin bahwa saya } \\
\text { teman yang baik" }\end{array}$ \\
\hline 3. & $\begin{array}{l}\text { "Saya adalah teman } \\
\text { yang tidak baik" }\end{array}$ & $\begin{array}{lcr}\text { "Apa } & \text { buktinya } & \text { saya } \\
\text { teman } & \text { yang } & \text { tidak } \\
\text { baik" } & & \end{array}$ & $\begin{array}{l}\text { "Saya yakin bahwa saya } \\
\text { teman yang baik" }\end{array}$ \\
\hline 4. & $\begin{array}{lr}\text { "Saya merasa sulit } \\
\text { mengikuti materi } \\
\text { pelajaran karena } \\
\text { kurang memiliki } \\
\text { kemampuan" }\end{array}$ & $\begin{array}{l}\text { "Siapa bilang saya } \\
\text { sulit mengikuti materi } \\
\text { pelajaran" }\end{array}$ & $\begin{array}{l}\text { "Saya yakin bahwa } \\
\text { mampu mengikuti materi } \\
\text { pelajaran" }\end{array}$ \\
\hline
\end{tabular}

Setelah intervensi subyek mengalami perubahn perilaku yang positif dari hari-kehari selama proses konseling. Yang telah digambarkan pada tabel diatas, bahwa sebeum intervensi w memiliki keyakinan irasional tentang kejadian pada saat dulu tidak berani menyapa teman. Melalui konseling w diarahkan untuk menantang keyakinan irasional dengan meyakini suatu keyakinan yang lebih irasional.

\section{Hasil Intervensi}

\begin{tabular}{|c|c|c|c|c|}
\hline No & $\begin{array}{l}\text { Perilaku sebelum } \\
\text { intervensi }\end{array}$ & \multicolumn{2}{|c|}{ Intervensi } & $\begin{array}{l}\text { Perilaku sesudah } \\
\text { intervensi }\end{array}$ \\
\hline 1. & $\begin{array}{l}\text { Merasa takut jika } \\
\text { berinteraksi dengan } \\
\text { teman }\end{array}$ & $\begin{array}{l}\text { Menantang } \\
\text { irasional, } \\
\text { keterampilan } \\
\text { relaksasi }\end{array}$ & $\begin{array}{r}\text { keyakinan } \\
\text { latihan } \\
\text { sosial, }\end{array}$ & $\begin{array}{l}\text { Lebih berani menyapa } \\
\text { teman terlebih dahulu }\end{array}$ \\
\hline 2. & $\begin{array}{l}\text { Tidak masuk kampus } \\
\text { atau bolos (karena tidak } \\
\text { nyaman berada di } \\
\text { kampus) }\end{array}$ & $\begin{array}{l}\text { Menantang } \\
\text { irasional }\end{array}$ & keyakinan & $\begin{array}{lr}\begin{array}{l}\text { Akan rajin } \\
\text { kampus }\end{array} & \text { masuk } \\
\text { dangan } \\
\text { menciptakan } & \text { suasana } \\
\text { yang nyaman di kampus }\end{array}$ \\
\hline
\end{tabular}




\begin{tabular}{|c|l|ll|l|}
\hline 3. & $\begin{array}{l}\text { Menghindari atau tidak } \\
\text { masuk kelas pada } \\
\text { materi tertentu (merasa } \\
\text { kurang mampu } \\
\text { menguasai pelajaran } \\
\text { karena guru kurang } \\
\text { jelas menerangkan) }\end{array}$ & $\begin{array}{l}\text { Menantang } \\
\text { irasional }\end{array}$ & $\begin{array}{l}\text { Akan mengikuti jadwal } \\
\text { materi pelajaran dengan } \\
\text { menggunakan sumber } \\
\text { tambahan buku }\end{array}$ \\
\hline 4. & $\begin{array}{l}\text { Tidak mengerjakan } \\
\text { tugas KTI (merasa guru } \\
\text { pembimbing kurang } \\
\text { jelas dalam } \\
\text { menerangkan) }\end{array}$ & $\begin{array}{l}\text { Menantang keyakinan } \\
\text { irasional }\end{array}$ & $\begin{array}{l}\text { Akan mengerjakan tugas } \\
\text { KTI dengan } \\
\text { menggunakan sumber } \\
\text { tambahan buku, internet. }\end{array}$ \\
\hline 5. & $\begin{array}{l}\text { Bersikap pasif dan } \\
\text { merasa masa bodoh } \\
\text { ketika berada di kelas } \\
\text { dan asrama }\end{array}$ & $\begin{array}{l}\text { Latihan keterampilan } \\
\text { sosial }\end{array}$ & $\begin{array}{l}\text { Lebih aktif berbincang } \\
\text { dengan kelompok teman } \\
\text { sebaya di kampus }\end{array}$ \\
\hline
\end{tabular}

Tabel diatas menjelaskan hasil intervensi yang berupa perilaku w sebelum dan sesudah konseling

\section{Pembahasan}

Berdasarkan penelitian yang dilakukan terhadap $\mathrm{W}$, dalam keseharian $\mathrm{W}$ di kampus menunjukkan penyesuaian diri yang buruk, yakni $\mathrm{W}$ cemas bila berinteraksi dengan teman sebaya, sering tidak masuk kampus atau membolos, menghindari atau tidak masuk kampus pada materi tertentu, tidak mngerjakan tugas atau PR, tidak mempunyai hubungan yang akrab secara emosional dengan teman sebaya. Hal ini sesuai dengan teori Haber dan Runyon (1984) menyatakan kriteria penyesuaian diri yang baik adalah: 1) Persepsi terhadap realitas yang akurat; 2) mampu mengatasi kecemasan; 3) gambaran diri yang positif; 4) kemampuan mengekspresikan perasaan; 5) hubungan interpersonal yang baik.

Penyesuaian diri yang buruk pada diri $\mathrm{W}$ disebabkan oleh beberapa faktor antara lain faktor kondisi fisik, kepribadian, pendidikan dan lingkungan. Hal ini sesuai dengan teori
Scheneiders (1980) yaitu sebagai berikut: 1) Faktor fisik terdiri dari: hereditas dan konstitusi fisik serta system utama tubuh yang berkembang dengan normal dan sehat. 2) Kepribadian, terdiri dari: kemauan dan kemampuan untuk berubah, kemampuan pengaturan diri, kemampuan pengaturan diri yang baik, kemampuan merealisasikan diri (seft-realization) serta intelegensi yang baik. 3) pendidikan, terdiri dari: kemauan belajar, pengalaman yang menyehatkan dan pengalaman traumatik (traumatic experinces), latihan yang sungguh-sungguh untuk menyesuaikan diri serta determinasi diri, yaitu kemampuan menentukan diri sendiri untuk menyesuaikan diri atau tidak, 4) lingkungan (keluarga, sekolah dan masyarakat).

Intervensi yang dilakukan pada subyek dengan menerapkan konseling pendekatan kognitif-behavioral yang menggunakan kemampuan kognitif subyek yang tergolong high average untuk memikirkan sendiri tentang 
perilaku yang akan dipertahankan dan akan di ubah. Beberapa teknik intervensi yang dinilai paling sesuai dengan keadaan subyek adalah: 1) menantang keyakinan irasional; 2) latihan relaksasi; 3) latihan keterampilan sosial (McLeod, 2010:157-158). Penerapan konseling dengan pendekatan kognitif-behavioral dinilai cukup efektif untuk meningkatkan penyesuaian diri W. Hal ini terlihat dari beberapa perubahan perilaku yang memenuhi target perubahan perilaku yaitu: 1) lebih berani menyapa teman terlebih dahulu; 2) rajin masuk kampus dengan menciptakan suasana yang nyaman di kampus; 3) mengikuti jadwal materi pelajaran dengan menggunakan sumber tambahan buku, internet.; 5) lebih aktif berbincang dengan kelompok teman sebaya di kampus.

\section{SIMPULAN}

1. Gambaran kesulitan penyesuaian diri pada $\mathrm{W}$

a) W cemas dan takut bila berinteraksi dengan teman sebaya

b) Tidak masuk kampus atau membolos

c) Menghindari atau tidak masuk kampus pada materi tertentu

d) Tidak mengerjakan tugas atau PR

e) Tidak mempunyai hubungan yang akrab secara emosional dengan teman sebaya

2. Faktor yang mempengaruhi penyesuaian diri pada $\mathrm{W}$ a) Kondisi fisik, yaitu: postur tubuh yang agak pendek, motorik tubuh yang lamban dan kaku serta sering sakit.

b) Kepribadian, yaitu: W merupakan individu yang introvert, mengalami ketakutan yang berlebihan, merasa kurang mampu mengalami hambatan kontaksosial, emosi yang kurang stabil serta gambaran yang negatif.

c) Pendidikan, yaitu: $\mathrm{W}$ belum mempunyai kemampuan belajar dan berlatih untuk menyesuaikan diri.

d) Lingkungan, yaitu: ketidak inkosisten pola asuh orangtua (pola asuh ayah yang otoriter dan ibu permisif), penolakan teman sebaya, kesepian merupakan faktor yang mempengaruhi penyesuaian diri $\mathrm{W}$.

3. Penerapan keefektifan konseling dengan pendekatan kognitif-behavioral

Teknik intervensi konseling dengan pendekatan kognitif-behavioral yang diterapkan kepada $\mathrm{W}$ adalah: 1) menantang keyakinan irasional; 2) latihan rileksasi; 3) latihan keterampilan sosial. Penerapan konseling dengan pendekatan kognitifbehavioral dinilai cukup untuk meningkatkan penyesuaian diri W. Hal ini terlihat dari beberapa perubahan perilaku yang memenuhi target perilaku, yaitu:

a) Lebih berani menyapa teman terlebih dahulu

b) Rajin masuk kampus

c) Mengikuti jadwal materi pelajaran Jurnal Ilmiah PSYCHE Vol.13 No.1 Juli 2019 : 13 - 23 
d) Megerjakan tugas (KTI atau karya ilmiah)

e) Lebih membina hubungan yang akrab dengan teman sebaya di kampus. 


\section{DAFTAR RUJUKAN}

Corey, Gerald .2009. Theory And Practice Of Counseling And Psychotherapy $8^{\text {th }}$ Edition. California: brooks/ Cole Cengage Learning

Gantina, Eka dan karsih .2011. Teori dan Teknik Konseling. Jakarta: Indeks

Gerungan. 2002. Psikologi Sosial. Bandung: Refika Aditama

Haber dan Ruyon (1984), Pshology of Adjusment.Iiionis: TheDorsey Press

Kartono,Kartini. 2003. Patalogi Sosial. Jakarta: RajaGrafindo

McLeod, John (2010). Pengantar Konseling Teori dan Praktek. Penerjemah: Anwar,A.K. Jakarta: Kencana Prenada Media Group

Poerwandari.1998. Pendekatan Kualitatif dalam PenelitianPsikologi. Depok: Lembaga Pengembangan Sarana Pengukuran dan Pendidikan Psikologi (LPSP 3) Universitas Indonesia

Yin,Robert.2011. Studi Kasus : Desain dan Metode.Jakarta : Rajagrafindo Persada 